\title{
Optimization of Process Parameters to Control Yarn Packing Density of Cotton Spun Yarn by Using Multiple Regression Models
}

\author{
${ }^{\mathrm{a}}$.Mohammad Ali Zeeshan , ${ }^{\mathrm{b}}$ Shouket Ali Adnan, ${ }^{\mathrm{a}}$ Sobia Faisal \\ ${ }^{a}$ Department of Textile Engineering, Balochistan University of Information Technology, Engineering \\ and Management Sciences, Quetta. \\ ${ }^{b}$ Merck Marker Pvt Ltd, Quetta. \\ Corresponding Author engr.zeeshan@ buitms.edu.pk
}

\begin{abstract}
Ring spinning frame is the most common and widely used technique for the production of yarn. This yarn subsequently utilized for the production of fabrics. Recently the research studies are more emphasis to create the living comfort condition. The yarn package density has a vital role to determine the feel, comfort, bulkiness and dyeing characteristics of the spun yarn. The yarn packaging density is largely influenced by the yarn process parameters. Ring spinning technique is the most common and widely used for the production of yarn. This yarn subsequently utilized for the production of fabrics. Recently the research studies are more emphasis to create the living comfort condition. The yarn package density is a vital role to determine the feel, comfort, bulkiness and dyeing characteristics of the spun yarn. It is largely influenced by the yarn manufacturing techniques and raw material used. The effects of spinning process parameters on packing density will be helpful to predetermine the yarn comfort behavior prior to the complete the fabric manufacturing process. Mechanical behavior of the staple yarn depends on the fiber characteristics and the yarn structure i.e. the arrangement of the individual fiber on the cross-section of the yarn. The fiber distribution on the cross section of the yarn and packing density of yarn has been investigated. The study provides how the spinning process parameters affect the internal structure of ring spun yarn. The aim of the study is to improve the package density of the yarn to achieve dynamometric and comfort properties of yarn to attract a wide variety of customers. Yarn Packing Density represents inter-fiber distance and friction, hence controlling the mechanical and comfort properties of the yarn. The main objective of this study is to control the packing density of yarn during the spinning process. In this work the 100 percent cotton used as raw material and spun on a ring spinning machine. The 135 ring yarns samples have been produced from three different types of yarn counts include (Ne 8, 16 and 24) with nine different samples of identical counts were produced. The three different variables within the count sample are TPI and spindle speed and count. Yarn packing density was calculated by using the driven equation by the application of multiple regression models. The final result shows that packing density has directly related to the TPI, Spindle speed and count..
\end{abstract}

Keywords- Count, IPI, packing density, process parameters, regression

Date Received 16 May 2019

Date Accepted 31 May 2019

Date Published 5 July 2019

\section{INTRODUCTION}

Cotton is vegetable fiber with many desired physical characteristics like strength; good comfort and dye pick up ability. it is suitable for making a wide range of textile goods. The approximately $50 \%$ to $56 \%$ of the clothing and household market portion is based on cotton. Cotton is also widely used in the non-woven industry for the manufacturing of textiles and special protective articles, which are preferred by the consumers.

The annual production of cotton is approximately 100 million bales around the world. Cotton production is nearly about 117 million bales recorded in the year 2006 and 2007 [1]. The yarn manufacturers are in need to produce the quality of yarn for the market. For the production of the quality yarn, it is necessary to check and test the cotton properties properly. Earlier the cotton was not tested due to which the quality of 
the textile yarn and fabric suffered. In the era of $80 \mathrm{~s}$ and $90 \mathrm{~s}$, the research has been done and investigated that cotton testing is the basic compulsion to get the best quality product.

At present, almost all the cotton bales have been tested not only in the United States but also in other quality yarn producing countries around the globe. The raw material has almost 50 percent of the total cost of the end product. Cotton fibers are firstly arranged into the different groups for the classification. It is done manually by sorting the material based on the area of cultivation. Different specimens taken from the different cotton lots and bales determine the cotton quality, which is randomly tested by using different testing instruments [2].

In this research work, the important physical properties of spun cotton yarn that is package density of yarn were studied and investigated its relationship with production process parameters. The optimization of spun cotton yarn, the precise evaluation of the production process was investigated at (different count, twist and production rate) and correlated each property with the quality parameter of the yarn. The spinner (producer) can easily optimize the required cotton yarn result prior to the complete spinning process.

\section{LITERATURE REVIEW}

\section{1) Importance of cotton fibers:-}

Cotton has its own versatile properties that are comfort, disability, and absorbency, etc. These qualities depend upon the selection of the cotton fiber used for the production of the desired product [1, 2].The cotton fiber characteristics are directly related to the yarn properties. The appropriate cotton fiber selection results in the yarn quality, whereas end-use properties are controlled through the raw material selection [3]. The cotton is used as garments for decades due to its social and cultural adaptability and medical compatibility. Due to the molecular structure, it has good absorbency properties. In the apparel industry near about $66 \%$ of cotton is consumed worldwide. [4].

\section{2) Importance of quality:-}

The quality of the product has a major role in the sustainability of the product in the market. The quality of textile products has a notable role in recent decades. To produce the quality of cotton spun yarn, it is necessary to select the appropriate raw cotton and machine. Otherwise, the producer could face deterioration in quality and machine performance. There exists a direct or indirect relationship between the production process parameters with the physical and mechanical properties of cotton yarn (evenness, hairiness, strength, imperfection, tenacity, work of rapture, elongation, lea strength product (bulk strength) [1-4]

\section{3) Ring spinning system:-}

The ring spinning technique is widely used amongst the other in Pakistan because it exhibits significant advantages in comparison with the new spinning systems. In the last century, several types of yarn production processes have been introduced and designed for cotton yarn spinning. however, the ring spinning not replaced by anyone because of firm control on the cotton yarn quality that can be optimized on the ring spinning system. These parameters not only affect during the weaving process but also in the dyeing and printing process [2].

\section{4) Process parameters and yarn quality relation:-}

The process involves in the manufacturing of the ring spinning yarn effecting the hairiness, strength and yarn imperfection of the yarn. The major role of the process machines like drawing frame, simplex and ring in the yarn quality entirely dominated to the machine roller setting that controls the fibers diameters and the fiber friction [3]. The strength of the cotton ring spun yarn depends upon the strength of the cotton fiber. Besides that, the twist of yarn has a major role in the strength properties of the yarn. Because of the compactness of fiber and the resulting of high tensile properties [4], the abrasion resistance, strength and the smooth appearance of the cotton fabric are dependent on the diameter of the yarn i.e. the cotton yarn count. Finer will be the count resulting smoother look and impart comfortable feel in woven fabrics [5]. The spindle speed has directly related to the hairiness of the ring spun yarn. It has a prominent effect on the yarn end breakage rate which affects the production efficiency as studied by the Xungai Wang1 in 2006 [6].

The study of process parameters in 2005 shows that the parameters like ring spindle speed, roving, and yarn twist have directly and indirectly affect the yarn hairiness \& imperfections [7]. The comforts of the cotton woven fabrics depend on the process parameters. The spindle speed and yarn twist multiplier directly related to the hairiness, air permeability and absorbency of cotton fabric as investigated by G K Tyagia in 2009 [8]. The optimization of spindle speed, the yarn count and the twist per inch i.e. the hardness and bulkiness of the yarn resulting from the better yarn quality.

\section{MeThodologY}

\section{1) Experimental work:-}

Pakistan cotton of the current crop was selected the hank roving of count $0.86 \mathrm{Ne}$ was used as an input package for all counts under study at the ring frame. For this experiment, the roving frame used was FL-16. 5 6 roving bobbins were used as input packages for yarn counts under study. All samples were spun on the ring frame Toyoda Rx-240. The threedifferent yarn counts of $8 \mathrm{~s}, 16 \mathrm{~s}$, and $24 \mathrm{~s}$ carded were produced. Every single carded yarn count was spun at different twist multiplier (8s at 3.45, 3.8 and 4.0), (16s at 3.8, 4.2 and 4.6) and (24s at 4.2, 4.6 and 4.9) at three different spindle speeds (8s at 9500, 10500 and $11500 \mathrm{rpm}),(16 \mathrm{~s}$ at 10500, 13500 and $16000 \mathrm{rpm})$ and (24s at 10500, 13500 and $16000 \mathrm{rpm})$. A total of 135 trails were done. The Suitable drafting ratio was set on the ring spinning machine for all samples, whereas the other spinning process condition were kept identical. The ring diameter of $46 \mathrm{~mm}$ was used and the suitable traveler was selected with respect to the spun yarn count. 


\section{2) Testing method:-}

The yarn parameters analyses tests, evenness, CV (coefficient of variation), number of faults (Thin-50\%, Thick $+50 \%$, and Neps $+200 \%$,), yarn density and yarn diameter were tested on. 2

Dimensional diameter, shape, density, the count was tested on Uster Tester 5. The TPI of each sample was checked on the digital Zewigller tester. The results were compiled and took the average, each flow set on the basis of the count so that the total no. of samples was only 27 . The testing results of 27 samples are shown in Table 1 . Then yarn packing density 10 was calculated using the following formula:

Packing density $=$ Specific volume of fibre Specific volume of yarn

Where

Specific volume $=250 \pi$ (Diameter) $^{2} \mathrm{~cm} 3 / \mathrm{g} \mathrm{(2)}$ tex

Taking cotton density as $1.52 \mathrm{~g} / \mathrm{cm} 3$, we get

Packing density $=$. Tex $380 \pi$ (diameter) $^{2}$

The moisture content and relative humidity affect the properties of the yarn. It also affects the structure of the cotton yarn and induces changes in the diameter of the yarn. During the testing, the relative humidity percentage. The standard atmospheric condition for the testing is the temperature ranges $20 \pm 2{ }^{\circ} \mathrm{C}$ and R.H $65 \pm 2 \%$ [1].

\section{3) Statistical methods:-}

The most commonly used statistical technique for establishing the relationship between the dependent and independent variables is regression analysis. The advantage of this method is to simplify and describe the quantitative relation between cotton yarn properties. So that the method of multiple linear regression analysis was used to establish this relationship between the process and the yarn quality parameters. Firstly, the type of relationship between the independent variable (process parameters) and dependent variable (yarn properties) was analyzed independently by using the linear line correlation analysis. It was found that a linear relationship exists between the process parameters and properties of the yarn. Therefore, the multiple linear regression method was selected for this research work.

\section{Results and Discussion}

Following are the testing results and the graph represents the relations in Column charts built by using the yarn testing results.

Table 1: value of dependent (Packing density) and independent variables

A. The effect of spindle speed on yarn packing density:

\begin{tabular}{|r|c|c|c|l|c|}
\hline S/No & Packing density & $\begin{array}{c}\text { Packing } \\
\text { density X }\end{array}$ & Count & $\begin{array}{l}\text { spindle } \\
\text { speed }\end{array}$ & Tpi \\
\hline 1 & 0.220912647 & 7731.942655 & 7.94 & 9500 & 9.718 \\
\hline 2 & 0.215182533 & 7531.388652 & 8.03 & 10500 & 9.786 \\
\hline 3 & 0.227835862 & 7974.255156 & 8.09 & 11500 & 9.704 \\
\hline 4 & 0.261606714 & 9156.234979 & 7.81 & 9500 & 10.602 \\
\hline 5 & 0.258445332 & 9045.58663 & 7.81 & 10500 & 10.796 \\
\hline 6 & 0.250733933 & 8775.687649 & 7.89 & 11500 & 10.698 \\
\hline 7 & 0.258170473 & 9035.966547 & 7.85 & 9500 & 11.68 \\
\hline 8 & 0.276447438 & 9675.660328 & 7.83 & 10500 & 11.456 \\
\hline 9 & 0.279847619 & 9794.666672 & 7.8 & 11500 & 11.66 \\
\hline 10 & 0.24714282 & 8649.998717 & 15.79 & 10000 & 15.072 \\
\hline 11 & 0.246362698 & 8622.694428 & 15.84 & 13000 & 15.622 \\
\hline 12 & 0.273385498 & 9568.492426 & 16.12 & 15800 & 14.816 \\
\hline 13 & 0.290564978 & 10169.77422 & 15.63 & 10000 & 16.706 \\
\hline 14 & 0.295789319 & 10352.62617 & 15.83 & 13000 & 16.484 \\
\hline 15 & 0.276851013 & 9689.785461 & 16.11 & 15800 & 16.77 \\
\hline 16 & 0.305729584 & 10700.53544 & 15.41 & 10000 & 18.392 \\
\hline 17 & 0.315087062 & 11028.04717 & 15.62 & 13000 & 18.452 \\
\hline 18 & 0.309747276 & 10841.15466 & 15.99 & 15800 & 18.358 \\
\hline 19 & 0.270359899 & 9462.59645 & 23.67 & 10000 & 21.064 \\
\hline 20 & 0.278535833 & 9748.754172 & 24 & 13000 & 20.748 \\
\hline 21 & 0.290758479 & 10176.54676 & 24.04 & 15800 & 20.646 \\
\hline 22 & 0.294929697 & 10322.53941 & 23.7 & 10000 & 21.14 \\
\hline 23 & 0.311091244 & 10888.19354 & 24.07 & 13000 & 22.592 \\
\hline 24 & 0.31073741 & 10875.80936 & 24.67 & 15800 & 22.496 \\
\hline 25 & 0.323055661 & 11306.94813 & 23.36 & 10000 & 24.086 \\
\hline 26 & 0.340325476 & 11911.39167 & 23.82 & 13000 & 24.77 \\
\hline 27 & 0.320370968 & 11212.98389 & 24.7 & 15800 & 24.1 \\
\hline & & & & & \\
\hline
\end{tabular}

Graph represents that the above mentioned relations in Column charts built using yarn testing results.

Figure 1: Effect of Spindle Speed on Packing Density of Yarn

\section{Effect of Spindle Speed on Packing density of Yarn}

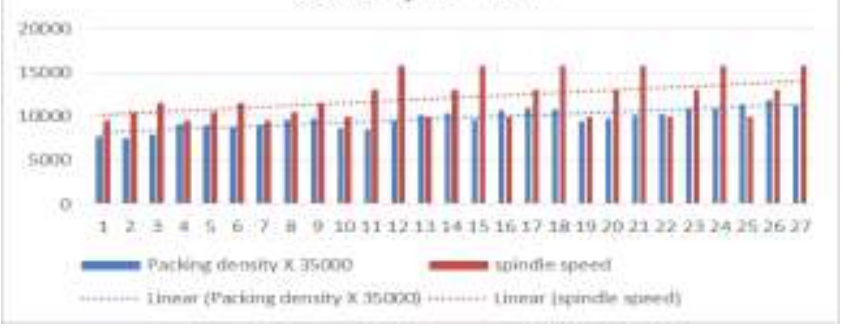

Trend line clearly depict that packing density and spindle speed are directly proportional to each other, The spindle speed has directly affect the yarn packing density during the yarn production process. The high spindle speed increase the 
yarn tension due the high tension the spinning triangle becomes shorter and the fiber binding in the yarn cross section is decreases so that the fibers come closer to each other and yarn packing density is increased.

\section{B. The effect of Count on yarn packing density:}

This graph was built using yarn testing results given in Table no 1 . To get the better graphical representation, Column chart was made between the spindle speed and yarn packing density.

Figure 2: Effect of Count on Packing Density of Yarn

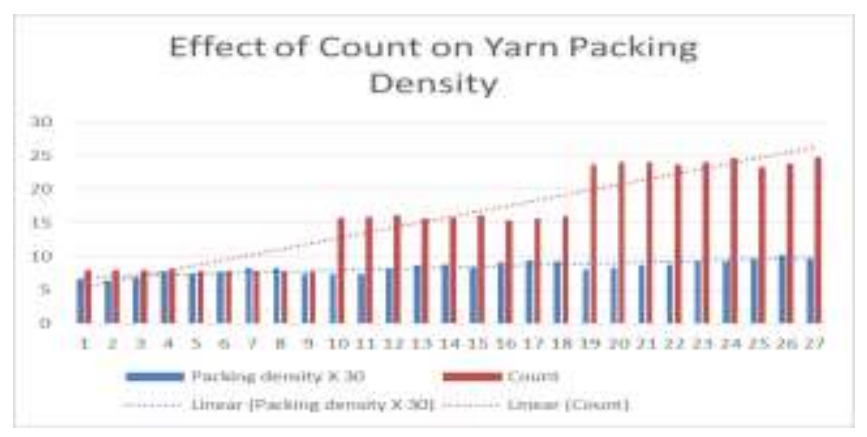

The Trend shows that there is constant increase in packing with increase in yarn count, hence result shows that the yarn packing density has direct relation with the yarn count. that packing density is affected by count. There is a direct relation between count and packing density. This correlation has been concluded through the multiple regression analysis by using the Minitab that there is positive correlation exists between the packing density and the count.

\section{The Effect of TPI on yarn packing density:}

After conducting the intensive research work we came to know the relation between yarn packing density and TPI. For the convenience values are given in the table no 1 and the results are also shown by the graphical representation.

Figure 3: Effect of TPI on Packing Density of Yarn Effect of TPI on Yarn Packing Density

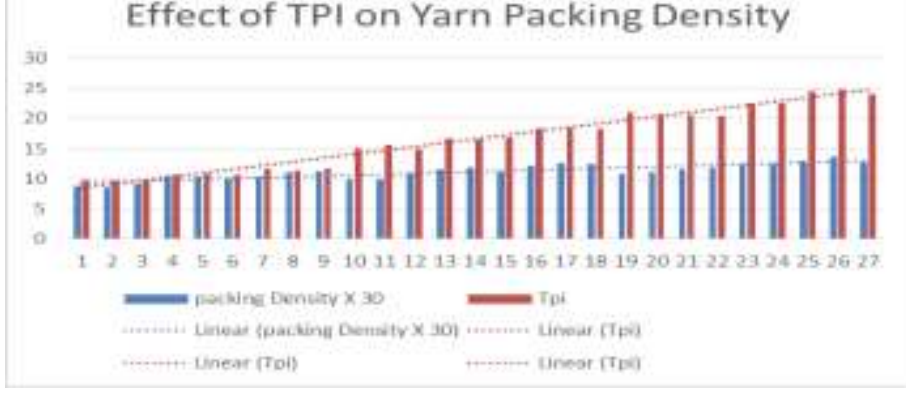

The Trend line shows direct relation between the variables, Such as the amount of TPI increases the yarn packing density is increases and vice versa. Due to the high twist value the tension (angular) and the tension amongst the fiber orientation in cross section of the fibers is increases which resulting the increase the yarn packing density.

\section{Multiple Regression Analysis:}

The multiple linear regression analysis of the three-different variables with the yarn

The three R-square values show their correlation significance. Each coefficient of the variables indicates the change in mean response. The standard error coefficient SE is positive and smaller value indicates the precise estimation. The t-value is calculated by dividing the coefficient by its standard error. The T-value differs from the zero; indicate that the coefficient is significant. The P-value of the coefficients less than 0.05 indicate its statistically significant relationship between predicators and its response.

\begin{tabular}{|c|c|c|c|c|c|c|c|}
\hline $\begin{array}{l}\text { Value } \\
\text { Term }\end{array}$ & Co-efficient & $\begin{array}{l}\text { SE Co- } \\
\text { efficien } \\
t\end{array}$ & $\begin{array}{l}\text { Value } \\
\text { of T }\end{array}$ & $\begin{array}{l}\text { Value } \\
\text { of P }\end{array}$ & $\mathrm{R} 2$ & $\begin{array}{l}\text { R2 } \\
\text { (adjus } \\
\text { t) }\end{array}$ & $\begin{array}{l}\mathrm{R} 2 \\
\text { (pred) }\end{array}$ \\
\hline Constant & 0.21025 & $\begin{array}{l}0.0685 \\
1\end{array}$ & 3.07 & 0.006 & \multirow{3}{*}{$\begin{array}{l}90.2 \\
\%\end{array}$} & \multirow{3}{*}{$\begin{array}{l}87.9 \\
\%\end{array}$} & \multirow{3}{*}{$\begin{array}{l}90.6 \\
\%\end{array}$} \\
\hline Count & 0.0002928 & $\begin{array}{l}0.0006 \\
604\end{array}$ & -0.44 & 0.662 & & & \\
\hline $\begin{array}{l}\text { spindle } \\
\text { speed }\end{array}$ & 0.00000013 & $\begin{array}{l}0.0000 \\
0115\end{array}$ & -0.11 & 0.910 & & & \\
\hline
\end{tabular}

The regression equation is

Packing density $=0.2100-0.0002933$ count -0.000000133 spindle speed $+0.00633 \mathrm{TPI}$

\section{CONCLUSION}

The type of relationship between yarn properties (dependent variable) with the process parameters (independent variables). During this research, the experimental analysis proves that there is a significant effect of the spinning process parameters. The spindle speed, yarn Twist Multiplier, and yarn count have a direct relation with the Packing density of a yarn.

Adjusting these variables will help us a lot to control the Packing density of yarn which will allow us to get desired properties in the fabric manufacturing process. To increase the TPI, Spindle speed and count resulting in an increase in yarn packing density of the yarn and vice versa.

\section{REFERENCES}

T. H. a. M. Bilal, "Critical characteristics of cotton that affect yarn quality in Ring Spinning,"pakistan textile journal vol.1, pp. http://wow/2008/0508/Tanveer\%20Hussain.htm, 8 May 2008 5/8/2008.

[2] R. Steadman, "Cotton testing," Textile progress, vol. 27, pp. 1-63, 1997. 
[3] Y. E. El Mogahzy and Y. Gowayed, "Theory and Practice of Cotton Fiber Selection Part I: Fiber Selection Techniques and Bale Picking Algorithms," Textile research journal, vol. 65, pp. 32-40, 1995.

[4] D. N. A. Memon, "Pakistan Spinning industry rank 3rd in the field of global yarn production," Pakistan textile Journal vol. February 2016, pp. 50-51, $02-$ 2016.

[5] L. A. Fiori and J. N. Grant, "Cotton Fibre Tensile Stiffness and Toughness Effects on Yarn Properties," Journal of the Textile Institute Proceedings, vol. 54, pp. P79-P91, 1963.

[6] J. M. Stewart, D. Oosterhuis, J. J. Heitholt, and J. R. Mauney, Physiology of cotton: Springer Science \& Business Media, 2009.

[7] O. L. May, "Quality Improvement of Upland Cotton (Gossypium hirsutumL.)," Journal of Crop Production, vol. 5, pp. 371-394, 2002.

[8] A. Babay, M. Cheikhrouhou, B. Vermeulen, B. Rabenasolo, and J. M. Castelain, "Selecting the optimal neural network architecture for predicting cotton yarn hairiness," The Journal of The Textile Institute, vol. 96, pp. 185-192, 2005/06/01 2005.

[9] H. Souid, A. Babay, M. Sahnoun, and M. Cheikrouhou, "A comparative quality optimization between ring spun and slub yarns by using desirability function," AUTEX Research Journal, vol. 8, pp. 72-76, 2008.

[10] H. G. Ortlek and S. Ulku, "Effect of Some Variables on Properties of $100 \%$ Cotton Vortex Spun Yarn," Textile Research Journal, vol. 75, pp. 458-461, 2005.

[11] A. Kumar, K. R. Salhotra, and S. M. Ishtiaque, "Analysis of spinning process using the Taguchi method. Part V: Effect of spinning processvariables on physical properties of ring, rotor and air-jet yarns," The Journal of The Textile Institute, vol. 97, pp. 463-473, 2006/10/01 2006.

[12] S. M. Ishtiaque, A. Das, and R. Niyogi, "Optimization of Fiber Friction, Top Arm Pressure and Roller Setting at Various Drafting Stages," Textile Research Journal, vol. 76, pp. 913-921, 2006.

[13] G. Basal and W. Oxenham, "Comparison of properties and structures of compact and conventional spun yarns," Textile Research Journal, vol. 76, pp. 567-575, 2006.

[14] J. Feng, B. Xu, and X. Tao, "A comparative study of finer conventional and modified cotton yarns and their resultant woven fabrics," Fibers and Polymers, vol. 14, pp. 1899-1905, 2013.

[15] Z. X. Tang, "The Effect of Yarn Hairiness on Air Drag in Ring Spinning," Textile Research Journal, vol. 76, pp. 559-566, 2006.

[16] Hasanuzzaman, P. K. Dan, and S. Basu, "Optimization of ring-spinning process parameters using response surface methodology," The Journal of The Textile Institute, vol. 106, pp. 510-522, 2015/05/04 2015.

[17] G. Tyagi, S. Bhattacharyya, M. Bhowmick, and R. Narang, "Study of cotton ring-and compact-spun yarn fabrics: Part II-Effects of spinning variables on comfort characteristics," 2010. 